\title{
Bronchoalveolar lavage pepsin in acute exacerbation of idiopathic pulmonary
}

\section{fibrosis}

\author{
J.S. Lee*, J.W. Song ${ }^{\#}$, P.J. Wolters*, B.M. Elicker", T.E. King Jr*, \\ D.S. Kim ${ }^{\#}$ and H.R. Collard*
}

ABSTRACT: Some patients with idiopathic pulmonary fibrosis experience acute exacerbations in their respiratory status leading to substantial morbidity and mortality. Occult aspiration of gastric contents has been proposed as one possible mechanism leading to these acute exacerbations. We sought to determine whether pepsin, a marker of gastric aspiration, is elevated in bronchoalveolar lavage fluid obtained from patients during acute exacerbation of idiopathic pulmonary fibrosis, compared with that obtained in stable disease.

Lavage samples were obtained in a case-control study of well-characterised patients. Acute exacerbation was defined using standard criteria. Levels of lavage pepsin were compared in cases and controls, and were correlated with clinical features and disease course.

24 cases with acute exacerbations and 30 stable controls were identified. There were no significant differences in baseline demographics between the two groups. Pepsin level was an indicator of acute exacerbation status $(p=0.04)$. On average, pepsin appeared higher in patients with acute exacerbations compared with stable controls. This difference was driven by a subgroup of eight patients (33\%) with pepsin levels $\geqslant 70 \mathrm{ng} \cdot \mathrm{mL}^{-1}$. Pepsin level was not an independent predictor of survival time.

These results suggest occult aspiration may play a role in some cases of acute exacerbation of idiopathic pulmonary fibrosis.

KEYWORDS: Acute lung injury, aspiration, gastro-oesophageal reflux, idiopathic pulmonary fibrosis

diopathic pulmonary fibrosis (IPF) is the most common form of idiopathic interstitial pneumonia, with a prevalence of $14-42.7$ per 100,000 [1]. There is no established therapy and the median survival from the time of diagnosis is $\sim 3$ yrs $[2,3]$. The natural history of IPF has historically been viewed as one of gradual progression, characterised by a steady decline in lung function over time. More recently it has been recognised that many patients may experience acute deteriorations in their respiratory status after periods of relative stability [4]. When no obvious precipitating cause is identified (e.g. infection or pulmonary embolism), these acute deteriorations have been termed acute exacerbations of IPF. Acute exacerbations of IPF are characterised by evidence of new ground-glass opacities on high-resolution computed tomography (HRCT) scan and diffuse alveolar damage (DAD) on surgical lung biopsy [4-6].
Occult aspiration of gastric contents secondary to gastro-oesophageal reflux has been proposed as one possible cause of acute exacerbation of IPF [4, 7]. Previous studies have suggested that the majority of patients with IPF have gastro-oesophageal reflux [8-10]. Gastro-oesophageal reflux is suspected to be a risk factor for pulmonary aspiration [11]. Aspiration of gastric contents can cause acute lung injury, manifested by DAD on lung biopsy [12].

Gastric pepsin is a proteolytic enzyme secreted by gastric chief cells and mucus neck cells as inactive pepsinogen. Bronchoalveolar lavage (BAL) pepsin has been shown to be a useful biomarker for gastric aspiration in post-lung transplant [13, 14], paediatric [15], asthmatic [16] and mechanically ventilated populations [17]. In particular, BAL pepsin has been shown to be a highly specific $(100 \%)$ and sensitive (80\%) method for diagnosing
AFFILIATIONS

Depts of *Medicine, and

"Radiology, University of California San Francisco, San Francisco, CA, USA

\# Dept of Pulmonary and Critical Care Medicine, Asan Medical Center, Ulsan University, Seoul, South Korea.

CORRESPONDENCE

H.R. Collard

505 Parnassus Avenue

Box 0111

San Francisco

CA 94143

USA

E-mail: hal.collard@ucsf.edu

D.S. Kim

Dept of Pulmonary and Critical Care Medicine

Asan Medical Center

86 Ansan byungwon-gil

Songpa-gu

Seoul

South Korea

E-mail: dskim@amc.seoul.kr

Received:

Mar 222011

Accepted after revision:

Oct 312011

First published online:

Dec 192011 
gastro-oesophageal reflux-associated aspiration in children [15]. Gastric pepsin can be detected in the BAL of some normal healthy subjects at very low levels (up to $2.6 \mathrm{ng} \cdot \mathrm{mL}^{-1}$ ) [18]. We hypothesised that BAL pepsin levels would be elevated in some patients with acute exacerbation of IPF compared to stable IPF, suggesting that aspiration of gastric contents contributed to a subgroup of acute exacerbations.

\section{MATERIALS AND METHODS}

\section{Study design and patient population}

This was a case-control study of patients with acute exacerbation of IPF and stable IPF seen at Asan Medical Center (Seoul, South Korea) from 2000 to 2009 . The subjects were enrolled into an institutional review board-approved longitudinal cohort study investigating IPF. Informed consent was obtained for all patients.

The diagnosis of IPF was made by multi-disciplinary review according to modified consensus criteria [19]. Stable IPF was defined as a patient with IPF who was not having an exacerbation at the time of BAL. BAL was obtained around the time of the initial IPF diagnosis (median difference in time between IPF diagnosis and BAL was -1 day, interquartile range (IQR) -913 days). These patients were randomly selected from a larger cohort as the control population. The diagnosis of acute exacerbation of IPF was made according to published criteria [4]. Briefly, acute exacerbation was defined by worsening respiratory symptoms within 30 days, new bilateral groundglass opacities on HRCT, and no evidence of an alternative aetiology. BAL was obtained shortly after admission (median difference in time between admission and BAL 1 day, IQR 14 days). All patients with acute exacerbation of IPF and BAL fluid available were included in this study.

Patient demographics, history of tobacco use (categorised as never, former and current smokers), body mass index (BMI), and pulmonary function values were recorded. Disease comorbidities were recorded as present or absent based on patient or physician reporting of the disease. Patient characteristics and vital status were obtained using the patient's medical record.

\section{Bronchoscopy and BAL pepsin measurement}

BAL was performed as previously reported [20]. For acute exacerbation cases, BAL was performed as part of the diagnostic evaluation of the patient's acute respiratory symptoms. For stable IPF controls, BAL was performed as part of the initial diagnostic evaluation of their interstitial lung disease. For both cases and controls, BAL was performed in a single sub-segment of the right middle lobe or lingula, with at least $100 \mathrm{~mL}$ of sterile saline instilled. The BAL fluid was kept on ice and processed within $1 \mathrm{~h}$ of collection then frozen at $-80^{\circ} \mathrm{C}$. BAL pepsin levels were measured using a commercially available ELISA (USCN Life Science, Wuhan, China).

\section{Radiology review}

All HRCT scans were reviewed by a radiologist blinded to the status (case or control) and clinical course of all subjects. Extent of ground-glass opacity, consolidation, honeycombing and reticulation, and overall computed tomography (CT) score, were determined [21]. The presence and size (craniocaudal length and diameter) of hiatal hernia, a known risk factor for gastrooesophageal reflux [22], was also determined. The craniocaudal dimension was measured from the superior-most image on which the hiatal hernia was present to the level of the oesophageal hiatus. The diameter was measured at the largest transverse dimension of the intrathoracic component of the hiatal hernia.

\section{Statistical analysis}

Descriptive statistics are presented as mean \pm SD or median (IQR). Inter-group comparisons were performed using the unpaired $\mathrm{t}$ test, Mann-Whitney rank sum test, Chi-squared test or Fisher's Exact test as appropriate. Logistic regression analysis was used to identify predictors of acute exacerbation status. Linear regression analysis was used to analyse the association between independent variables and BAL pepsin level. Cox proportional hazard modelling was performed to identify predictors of survival time in the acute exacerbation cohort. Survival time was calculated from the time of BAL until death or time of censoring. Analysis was also performed using pepsin as a dichotomous variable, using the 95th percentile value from the stable IPF group as the threshold value. All data analysis was performed using Stata version 11 (StataCorp, College Station, TX, USA). All tests were two-sided and performed at a significance level of 0.05 .

\section{RESULTS}

\section{Clinical, radiological and BAL features of cases and controls}

A total of 24 acute exacerbation of IPF cases and 30 stable IPF controls were identified. There were no significant differences in baseline demographics between the two groups, including age, sex, smoking status, BMI and reported comorbidities (table 1).

There were significant differences in ground-glass opacity score $(\mathrm{p}<0.01)$, consolidation score $(\mathrm{p}<0.01)$, reticulation score $(\mathrm{p}<0.01)$, and overall CT score $(\mathrm{p}<0.01)$ between the two groups (table 2). There was no significant difference in the honeycombing score between the two groups. There was no difference between the two groups in the prevalence or size of radiologically identified hiatal hernia.

The BAL fluid was clear and none of the samples had obvious blood on gross examination. The BAL red blood cell (RBC) count was higher in the acute exacerbation group compared with the stable group $(\mathrm{p}<0.01)$. There was no difference in BAL total cell count between the two groups (table 2). There was a higher percentage of BAL neutrophils $(p=0.02)$ and a lower percentage of BAL macrophages $(p<0.01)$ in the acute exacerbation group compared with the stable group.

\section{Indicators of acute exacerbation status}

The median level of BAL pepsin in the acute exacerbation of IPF cases was $46.8 \mathrm{ng} \cdot \mathrm{mL}^{-1}$, compared with $35.4 \mathrm{ng} \cdot \mathrm{mL}^{-1}$ in the stable IPF controls $(p=0.15)$ (fig. 1). On bivariate regression, a 1-unit increase in BAL pepsin was an indicator of acute exacerbation status (OR 1.02, 95\% CI 1.001-1.03; $p=0.04$ ). An increase in BAL pepsin level by one standard deviation $\left(24.8 \mathrm{ng} \cdot \mathrm{mL}^{-1}\right)$ was associated with an odds ratio of 1.46 (95\% CI 1.03-2.09; $\mathrm{p}=0.04)$ for acute exacerbation status.

There were no clinical variables associated with acute exacerbation status (table 3). There was no association of prevalence or size of radiological hiatal hernia with acute exacerbation status. Elevated BAL neutrophil percentage and decreased BAL alveolar 


\begin{tabular}{|c|c|c|c|}
\hline & Stable IPF & Acute exacerbation of IPF & p-value \\
\hline Subjects n & 30 & 24 & \\
\hline Age yrs & $65 \pm 8$ & $64 \pm 9$ & 0.91 \\
\hline Male & $77 \%(23)$ & $79 \%(19)$ & 0.83 \\
\hline \multicolumn{4}{|l|}{ Smoking history } \\
\hline Never-smoker & $27 \%(8)$ & $21 \%(5)$ & 0.62 \\
\hline Former smoker & $60 \%(18)$ & $71 \%(17)$ & 0.41 \\
\hline Current smoker & $13 \%(4)$ & $8 \%(2)$ & 0.56 \\
\hline $\begin{array}{l}\text { Current alcohol } \\
\text { use }\end{array}$ & $43 \%(13)$ & $54 \%(13)$ & 0.43 \\
\hline Body mass index & $24.5 \pm 3.8$ & $25.2 \pm 4.0$ & 0.56 \\
\hline \multicolumn{4}{|l|}{ Comorbidities } \\
\hline CAD & $3 \%(1)$ & $13 \%(3)$ & 0.20 \\
\hline GERD & $0 \%(0)$ & $8 \%(2)$ & 0.11 \\
\hline OSA & $0 \%(0)$ & $0 \%(0)$ & \\
\hline $\mathrm{PH}$ & $7 \%(2)$ & $4 \%(1)$ & 0.69 \\
\hline \multicolumn{4}{|l|}{ Medications } \\
\hline Prednisone $e^{\#}$ & $17 \%(10)$ & $63 \%(15)$ & $<0.01$ \\
\hline PPI & $0 \%(0)$ & $4 \%(1)$ & 0.23 \\
\hline H2 blockers & $20 \%(6)$ & $38 \%(9)$ & 0.15 \\
\hline Oestrogen & $0 \%(0)$ & $4 \%(1)$ & 0.26 \\
\hline TLC \% pred & $78.5 \pm 12.0$ & NA & \\
\hline FVC \% pred & $79.6 \pm 16.4$ & NA & \\
\hline DL,Co \% predicted & $68.8 \pm 17.4$ & NA & \\
\hline Intubated" & $0 \%(0)$ & $8 \%(2)$ & 0.11 \\
\hline \multicolumn{4}{|c|}{$\begin{array}{l}\text { Data are presented as } \%(n) \text { or mean } \pm S D \text {, unless otherwise stated. IPF: } \\
\text { idiopathic pulmonary fibrosis; CAD: coronary artery disease; GERD: gastro- } \\
\text { oesophageal reflux disease; OSA: obstructive sleep apnoea; PH: pulmonary } \\
\text { hypertension; PPI: proton pump inhibitor; } \mathrm{H} 2 \text { : histamine } 2 \text { receptor; TLC: total } \\
\text { lung capacity; \% pred: \% predicted; FVC: forced vital capacity; } D L \text {, CO: diffusing } \\
\text { capacity of the lung for carbon monoxide. }{ }^{\#} \text { : prednisone use at the time of } \\
\text { bronchoalveolar lavage; " : intubated state at the time of bronchoalveolar } \\
\text { lavage. }\end{array}$} \\
\hline
\end{tabular}

macrophage percentage were indicators of acute exacerbation status. After adjusting for BAL neutrophil percentage, BAL pepsin level remained an indicator of acute exacerbation status (OR 1.02, 95\% CI 1.002-1.03; $\mathrm{p}=0.03$ ).

\section{BAL pepsin levels and acute exacerbation}

Eight (33\%) of the acute exacerbation of IPF cases had high BAL pepsin levels (i.e. above the 95th percentile of the stable control population, $70 \mathrm{ng} \cdot \mathrm{mL}^{-1}$ ). There were no significant differences in baseline clinical characteristics, including history of gastrooesophageal reflux or aspiration, use of prednisone or antireflux medications, and survival time, between the high- and low-pepsin acute exacerbation cases (table 4). Two subjects in the acute exacerbation group were intubated at the time of BAL. Their BAL pepsin levels were in the low BAL pepsin group (36.8 $\mathrm{ng} \cdot \mathrm{mL}^{-1}$ and $31.8 \mathrm{ng} \cdot \mathrm{mL}^{-1}$, respectively). There were also no significant differences in the presence of radiological hiatal hernia, the percentage of ground-glass opacities, consolidation or reticulation between the two groups. The high BAL pepsin group had a higher percentage of BAL lymphocytes compared

\begin{tabular}{|c|c|c|c|}
\hline \multirow[t]{2}{*}{ TABLE 2} & \multicolumn{3}{|c|}{$\begin{array}{l}\text { \# and bronchoalveolar lavage fluid } \\
\text { es }\end{array}$} \\
\hline & Stable IPF & $\begin{array}{l}\text { Acute exacerbation } \\
\text { of IPF }\end{array}$ & p-value \\
\hline Subjects $n$ & 30 & 24 & \\
\hline \multicolumn{4}{|l|}{ Radiological features } \\
\hline Hiatal hernia prevalence & $57 \%(17)$ & $67 \%(16)$ & 0.45 \\
\hline Hiatal hernia diameter $\mathrm{cm}$ & $1.4(0-1.5)$ & $1.5(0-1.6)$ & 0.39 \\
\hline Hiatal hernia height $\mathrm{cm}$ & $1.0(0-2.0)$ & $2.0(0-2.5)$ & 0.29 \\
\hline Ground-glass opacity score \% & $2(0-5)$ & $18(6-27)$ & $<0.01$ \\
\hline Consolidation score \% & $0(0-0)$ & $0(0-3)$ & $<0.01$ \\
\hline Honeycombing score \% & $4(1-9)$ & $6(3-12)$ & 0.17 \\
\hline Reticulation score \% & $6(3-8)$ & $9(5-27)$ & $<0.01$ \\
\hline Overall CT score \% & $13(8-23)$ & $43(26-63)$ & $<0.01$ \\
\hline \multicolumn{4}{|l|}{ BAL fluid features } \\
\hline Pepsin concentration $\mathrm{ng} \cdot \mathrm{mL}^{-1}$ & $35.4(14.5-55.6)$ & $46.8(18.9-92.0)$ & 0.15 \\
\hline Total cell count cells $\cdot \mathrm{mL}^{-1}$ & $254(140-380)$ & $270(150-380)$ & 0.84 \\
\hline \multicolumn{4}{|l|}{ Neutrophils } \\
\hline$\%$ & $6(2-10)$ & $13(6-28)$ & 0.02 \\
\hline Cells $\cdot \mathrm{mL}^{-1}$ & $11(6-23)$ & $25(8-63)$ & \\
\hline \multicolumn{4}{|l|}{ Lymphocytes } \\
\hline$\%$ & $10(7-18)$ & $17(6-32)$ & 0.25 \\
\hline Cells $\cdot \mathrm{mL}^{-1}$ & $23(11-70)$ & $26(8-70)$ & \\
\hline \multicolumn{4}{|l|}{ Alveolar macrophages } \\
\hline$\%$ & $73(60-88)$ & $52(30-64)$ & $<0.01$ \\
\hline Cells $\cdot \mathrm{mL}^{-1}$ & $176(97-294)$ & 134 (39-195) & \\
\hline \multicolumn{4}{|l|}{ Eosinophils } \\
\hline$\%$ & $4(1-9)$ & $2(0-7)$ & 0.16 \\
\hline Cells $\cdot \mathrm{mL}^{-1}$ & $7(2-28)$ & $5(0-18)$ & \\
\hline $\begin{array}{l}\text { Red blood cell count } \\
\text { cells } \cdot \mathrm{mL}^{-1}\end{array}$ & $65(10-230)$ & $500(180-1500)$ & $<0.01$ \\
\hline
\end{tabular}

Data are presented as \% (n) or median (interquartile range), unless otherwise stated. IPF: idiopathic pulmonary fibrosis; CT: computed tomography. ${ }^{\#}$ : at the time of bronchoalveolar lavage.

with the low BAL pepsin group $(p<0.01)$. There was no significant difference in $\mathrm{RBC}$ count between those with low and high BAL pepsin levels $(\mathrm{p}=0.24)$.

Seven subjects in the acute exacerbation cohort also had previously undergone BAL at the time of IPF diagnosis (i.e. a corresponding stable sample). In this small subgroup, there was no overall relationship between stable (median $17.3 \mathrm{ng} \cdot \mathrm{mL}^{-1}$, IQR 0 $92.5 \mathrm{ng} \cdot \mathrm{mL}^{-1}$ ) and acute exacerbation (median $52.5 \mathrm{ng} \cdot \mathrm{mL}^{-1}$, IQR 8.5-63.6 ng. $\mathrm{mL}^{-1}$ ) BAL pepsin levels $(\mathrm{p}=0.61$; fig. 2). However, only one of the seven subjects had a high BAL pepsin level during their acute exacerbation $\left(220.8 \mathrm{ng} \cdot \mathrm{mL}^{-1}\right)$; this represented an approximately 10 -fold increase in BAL pepsin level compared to the subject's stable value $\left(23.8 \mathrm{ng} \cdot \mathrm{mL}^{-1}\right)$.

\section{Predictors of BAL pepsin level}

In the combined group of cases and controls, clinical variables including age, sex, history of gastro-oesophageal reflux, history of smoking, BMI, anti-reflux medication use, prednisone use and intubation status were not associated with BAL pepsin level (data not shown). Acute exacerbation status and increased reticulation 


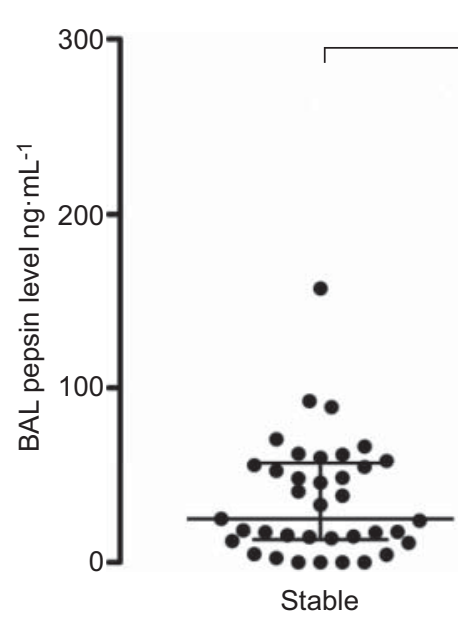

$p=0.15$

FIGURE 1. Bronchoalveolar lavage (BAL) pepsin levels in patients with stable idiopathic pulmonary fibrosis (IPF) compared with acute exacerbation of IPF. Horizontal lines represent median, 25th percentile and 75th percentile.

on HRCT were associated with higher BAL pepsin levels ( $\mathrm{p}=0.01$ and $\mathrm{p}=0.02$, respectively). No other radiological variables were significant indicators, including radiological hiatal hernia. Increased percentage of BAL lymphocytes was associated with increased BAL pepsin level $(\mathrm{p}<0.01)$. There was no association between BAL pepsin level and BAL RBC count $(p=0.79)$. Within the stable IPF cohort, there was no correlation between BAL pepsin levels and $\%$ predicted total lung capacity (TLC) $(\mathrm{p}=0.83$; fig. 3) or \% pred forced vital capacity (FVC) $(p=0.39)$.

\section{Survival}

The median (IQR) follow-up time in the acute exacerbation cohort was 74 (15-492) days. 30- and 60-day survival were $67 \%$

\begin{tabular}{llc} 
TABLE 3 & $\begin{array}{l}\text { Variables associated with acute exacerbation } \\
\text { status }\end{array}$ & \\
Variable & OR (95\% Cl) & \\
\hline Clinical & & \\
Age & $1.00(0.94-1.06)$ & 0.91 \\
Male sex & $1.16(0.32-4.24)$ & 0.83 \\
Body mass index & $1.04(0.91-1.20)$ & 0.55 \\
Never-smoker & $0.72(0.20-2.59)$ & 0.62 \\
Former smoker & $1.62(0.52-5.08)$ & 0.41 \\
Current smoker & $0.59(0.10-3.54)$ & 0.57 \\
Radiological & & \\
Hiatal hernia & $1.53(0.50-4.66)$ & 0.46 \\
Hiatal hernia height & $1.26(0.79-2.01)$ & 0.32 \\
Hiatal hernia diameter & $1.32(0.66-2.67)$ & 0.44 \\
BAL & & \\
BAL pepsin level & $1.02(1.001-1.03)$ & 0.04 \\
BAL neutrophils \% & $1.05(1.00-1.10)$ & 0.03 \\
BAL lymphocytes \% & $1.03(1.00-1.07)$ & 0.08 \\
BAL alveolar macrophages \% & $0.95(0.91-0.98)$ & $<0.01$ \\
\hline
\end{tabular}

BAL: bronchoalveolar lavage.

\begin{tabular}{|c|c|c|c|c|}
\hline \multirow[t]{2}{*}{ TABLE 4} & \multicolumn{4}{|c|}{$\begin{array}{l}\text { Comparison of characteristics between low and } \\
\text { high bronchoalveolar lavage (BAL) pepsin levels } \\
\text { in acute exacerbation of idiopathic pulmonary } \\
\text { fibrosis }\end{array}$} \\
\hline & & $\begin{array}{l}\text { Acute } \\
\text { exacerbation } \\
\text { pepsin low }\end{array}$ & $\begin{array}{l}\text { Acute } \\
\text { exacerbation } \\
\text { pepsin high }\end{array}$ & p-value \\
\hline Subjects $n$ & & 16 & 8 & \\
\hline \multicolumn{5}{|c|}{ Clinical characteristics } \\
\hline Age yrs & & $65 \pm 10$ & $63 \pm 8$ & 0.72 \\
\hline Male & & $69 \%(11)$ & $100 \%(8)$ & 0.13 \\
\hline Ever-smoke & & $75 \%(12)$ & $88 \%(7)$ & 0.63 \\
\hline Body mass & ndex & $25.9 \pm 4.0$ & $23.6 \pm 3.8$ & 0.19 \\
\hline Prednisone & & $56 \%(9)$ & $75 \%(6)$ & 0.66 \\
\hline Intubated & & $13 \%(2)$ & $0 \%(0)$ & 0.54 \\
\hline Survival tim & days & $75(21-459)$ & $65(10-615)$ & 0.78 \\
\hline Alive at follo & -up & $12 \%(2)$ & $25 \%(2)$ & 0.58 \\
\hline \multicolumn{5}{|c|}{ Radiological characteristics } \\
\hline Hiatal hernic & prevalence & $69 \%(11)$ & $63 \%(5)$ & 0.55 \\
\hline Hiatal hernia & diameter $\mathrm{cm}$ & $1.5(0-1.6)$ & $1.2(0-1.6)$ & 0.39 \\
\hline Hiatal hernic & height $\mathrm{cm}$ & $2(0-3)$ & $1(0-2.3)$ & 0.34 \\
\hline Ground-glas & opacity score \% & $18(6-33)$ & $18(7-26)$ & 0.82 \\
\hline Consolidatic & n score $\%$ & $0(0-2)$ & $2(0-8)$ & 0.16 \\
\hline Honeycomb & ng score $\%$ & $10(3-12)$ & $4(2-7)$ & 0.23 \\
\hline Reticulation & score $\%$ & $8(5-27)$ & $13(8-24)$ & 0.50 \\
\hline Overall CT s & core $\%$ & $45(28-63)$ & $43(24-58)$ & 0.65 \\
\hline \multicolumn{5}{|c|}{ BAL fluid characteristics } \\
\hline $\begin{array}{l}\text { Pepsin conc } \\
\mathrm{ng} \cdot \mathrm{mL}^{-1}\end{array}$ & entration & $30.3(6-46.8)$ & $\begin{array}{c}148.4(92.0- \\
227.0)\end{array}$ & $<0.01$ \\
\hline Total cell co & unt cells $\cdot \mathrm{mL}^{-1}$ & $235(144-372)$ & $340(150-400)$ & 0.53 \\
\hline Neutrophils & & $23(8-32)$ & $10(2-13)$ & 0.10 \\
\hline Lymphocyte & & $8(5-18)$ & $38(26-65)$ & $<0.01$ \\
\hline Alveolar ma & rophages \% & $57(38-65)$ & $46(22-56)$ & 0.11 \\
\hline Eosinophils & & $2(0-7)$ & $3(0-6)$ & 0.83 \\
\hline $\begin{array}{l}\text { Red blood c } \\
\text { cells } \cdot \mathrm{mL}^{-1}\end{array}$ & ell count & $770(244-5875)$ & $390(130-750)$ & 0.24 \\
\hline
\end{tabular}

Data are presented as mean $\pm S D$ or median (interquartile range), unless otherwise stated. CT: computed tomography.

and $58 \%$, respectively. Only $17 \%$ of the subjects in the acute exacerbation cohort were alive at the time of final analysis. Analysis of acute exacerbation cases revealed no significant predictors of survival time (table 5). Specifically, BAL pepsin level was not predictive of survival. Analysis of the stable IPF controls revealed a trend towards higher BAL pepsin levels in those that had died compared to those that were still alive (48.4 versus $18.3 \mathrm{ng} \cdot \mathrm{mL}^{-1} ; \mathrm{p}=0.10$ ).

\section{DISCUSSION}

This study addressed the relationship of occult aspiration to acute exacerbation in patients with IPF. Elevated BAL pepsin was predictive of acute exacerbation status on both bivariate and multivariate analysis, driven by the presence of a subgroup of cases $(33 \%)$ with markedly elevated pepsin levels. Although the relationship is modest, this finding provides evidence that occult aspiration may play a role in acute exacerbation of IPF. 


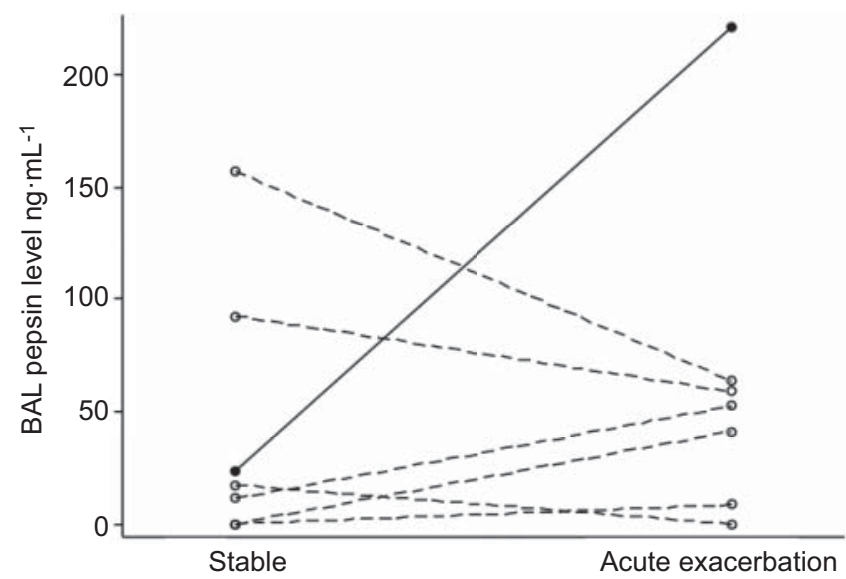

FIGURE 2. Bronchoalveolar lavage (BAL) pepsin levels in seven patients with matched stable and acute exacerbation of idiopathic pulmonary fibrosis BAL samples. Each line represents one study subject. The closed circles and solid line represent the subject who had a high BAL pepsin level during the acute exacerbation. The open circles and dashed lines represent those subjects who had low BAL pepsin levels during their acute exacerbations.

There is a growing interest in the role of gastro-oesophageal reflux and occult aspiration in patients with IPF [7]. It has been hypothesised that occult aspiration of gastric contents may contribute to the natural history of IPF. One case series described four patients with IPF whose clinical course stabilised (based on pulmonary function testing) after receiving medical therapy for gastro-oesophageal reflux [23]. Another study reviewed 14 patients with IPF awaiting lung transplantation and showed stabilisation of oxygen requirements in those patients who had a laparoscopic Nissen fundoplication [24]. These studies support a possible association of gastro-oesophageal reflux and occult aspiration with disease progression in IPF.

Our study extends this relationship in two ways. First, we found measurable BAL pepsin in most patients with stable IPF, suggesting that occult aspiration is common in IPF. Secondly, the association of elevated BAL pepsin with acute exacerbation status provides evidence that occult aspiration may play a role

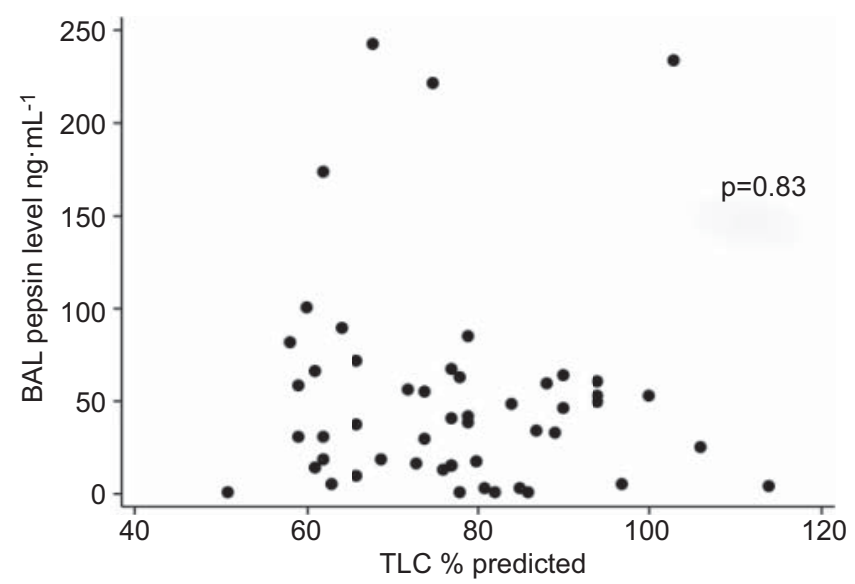

FIGURE 3. Correlation between bronchoalveolar lavage (BAL) pepsin levels and \% predicted total lung capacity (TLC).

\begin{tabular}{lll} 
TABLE $5 \begin{array}{l}\text { Impact of variables on survival in acute } \\
\text { exacerbation of idiopathic pulmonary fibrosis }\end{array}$ & \\
& HR-value \\
\hline Variable & & \\
\hline Clinical & & \\
Age & $0.97(0.92-1.02)$ & 0.19 \\
Male sex & $2.19(0.70-6.82)$ & 0.18 \\
Body mass index & $0.93(0.82-1.05)$ & 0.25 \\
Never-smoker & $0.56(0.16-1.94)$ & 0.36 \\
Former smoker & $1.28(0.46-3.58)$ & 0.64 \\
Current smoker & $1.76(0.40-7.85)$ & 0.46 \\
Radiological & & \\
Hiatal hernia & $0.74(0.27-2.01)$ & 0.55 \\
Hiatal hernia height & $0.91(0.60-1.38)$ & 0.66 \\
Hiatal hernia diameter & $0.77(0.42-1.44)$ & 0.42 \\
Ground-glass opacity score & $1.03(1.00-1.06)$ & 0.08 \\
Consolidation score & $1.04(0.94-1.14)$ & 0.43 \\
Reticulation score & $0.96(0.91-1.01)$ & 0.15 \\
Overall CT score & $1.02(0.99-1.05)$ & 0.21 \\
BAL & & \\
BAL pepsin level & $1.00(0.99-1.00)$ & 0.62 \\
BAL total cell count & $1.00(1.00-1.002)$ & 0.35 \\
BAL neutrophils \% & $1.02(1.00-1.05)$ & 0.05 \\
BAL lymphocytes \% & $0.99(0.96-1.02)$ & 0.44 \\
BAL alveolar macrophages \% & $0.99(0.97-1.01)$ & 0.52 \\
\hline
\end{tabular}

HR: hazard ratio; CT: computed tomography; BAL: bronchoalveolar lavage.

in the natural history of IPF, perhaps through causing some acute exacerbations. An alternative explanation for this association could be that acute respiratory decompensation leads to increased aspiration (and therefore elevated BAL pepsin levels) through increased intrathoracic pressure swings. In our stable IPF cohort, we found no correlation between the severity of disease, as measured by \% pred TLC and FVC, and BAL pepsin level. However, we do not have pulmonary function test results for the acute exacerbation cohort, and it is possible that microaspiration could occur in the setting of acute respiratory decompensation.

There were no clinical predictors of BAL pepsin level across cases and controls in this study. This finding is consistent with the known discordance between signs and symptoms of gastrooesophageal reflux and the presence of pathological reflux on oesophageal $\mathrm{pH}$ testing $[8,9]$. Importantly, we do not have functional oesophageal data (e.g. 24-h $\mathrm{pH}$ monitoring and manometry), so it is unknown whether cases with elevated BAL pepsin levels have altered oesophageal function. We found no difference in radiological hiatal hernia between the high and low BAL pepsin groups, which might have helped identify patients at risk for aspiration-related acute exacerbation. There was also no association between BAL pepsin level and survival in cases of acute exacerbation of IPF. This was not unexpected, as acute exacerbation of IPF is characterised by DAD, the natural history of which is likely to be independent of the underlying aetiology.

The BAL differential cell count was associated with acute exacerbation of IPF and BAL pepsin levels. Increased BAL neutrophil percentage was an indicator of acute exacerbation and was suggestive of worse survival. These findings are consistent with 
data previously published showing BAL neutrophilia is associated with reduced 1-yr survival in IPF [25]. Interestingly, the percentage of BAL lymphocytes was higher in acute exacerbation of IPF cases with high BAL pepsin levels. The significance of this finding is unclear, but it may suggest that more significant aspiration is associated with lymphocyte recruitment to the lung.

This study was not designed to identify risk factors for the development of acute exacerbation, and therefore does not identify an "at risk" population. Our limited number of acute exacerbation patients with paired samples $(n=7)$ suggest that baseline BAL pepsin levels are not predictive of future acute exacerbation, but this subgroup is underpowered to address this issue. Our data do not support obtaining BAL pepsin levels from stable patients. The relationship of baseline gastrooesophageal reflux and aspiration to future acute exacerbation should be the basis for future longitudinal studies.

We recognise that this study has other limitations. First, BAL pepsin is not a direct measure of aspiration. However, given that pepsin is not normally found in high levels in the lower respiratory tract, its measurement in BAL should be a useful biomarker of aspiration [15, 18, 26]. Secondly, BAL pepsin level may be affected by factors other than aspiration, such as contamination of the bronchoscope with upper airway secretions, variation in the concentration of BAL fluid, patient's position in bed, or recent intubation. These factors are partially controlled for by the inclusion of a stable IPF control group and standardised BAL technique. Thirdly, there is a theoretical concern that we could be detecting pepsinogen from a non-gastric source (i.e. the blood) due to cross-reactivity of the antibody. However, we found no correlation between the BAL RBC count and the BAL pepsin level. Fourthly, the site of the BAL was in either the right middle lobe or lingula, which was not necessarily the most diseased area by HRCT scan. It is possible that the BAL pepsin levels may have been higher had the most diseased area been sampled. Finally, given the use of chart review to ascertain medical comorbidities, we have most likely underestimated the prevalence of gastro-oesophageal reflux disease and the other comorbidities in this population.

In summary, this study demonstrates that BAL pepsin is elevated in a subgroup of patients with acute exacerbation of IPF. These findings support the hypothesis that occult aspiration of gastric contents plays a role in acute exacerbation of IPF. Future research should confirm these results in a larger, multicentre study.

\section{SUPPORT STATEMENT}

This study was supported by grants HL 973832 and HL 086516 from the National Heart, Lung and Blood Institute (Bethesda, MD, USA).

\section{STATEMENT OF INTEREST}

Statements of interest for D.S. Kim and H.R. Collard can be found at www.erj.ersjournals.com/site/misc/statements.xhtml

\section{ACKNOWLEDGEMENTS}

Author contributions were as follows. Involvement in conception, hypothesis and design of the study (J.S. Lee, T.E. King Jr, H.R. Collard); selection of the patients and acquisition of the samples (D.S. Kim), acquisition of the data (J.S. Lee, J.W. Song, B.M. Elicker, P.J. Wolters, D.S. Kim); analysis and interpretation of the data (J.S. Lee, P.J. Wolters, T.E. King Jr, D.S. Kim, H.R. Collard); substantial involvement in the writing and/or revision of the article (J.S. Lee, P.J. Wolters, T.E. King Jr, D.S. Kim, H.R. Collard). All authors approved of this version of the manuscript.

\section{REFERENCES}

1 Raghu G, Weycker D, Edelsberg J, et al. Incidence and prevalence of idiopathic pulmonary fibrosis. Am J Respir Crit Care Med 2006; 174: 810-816.

2 Bjoraker JA, Ryu JH., Edwin MK, et al. Prognostic significance of histopathologic subsets in idiopathic pulmonary fibrosis. Am J Respir Crit Care Med 1998; 157: 199-203.

3 King TE Jr, Tooze JA, Schwarz MI, et al. Predicting survival in idiopathic pulmonary fibrosis: scoring system and survival model. Am J Respir Crit Care Med 2001; 164: 1171-1181.

4 Collard HR, Moore BB, Flaherty KR, et al. Acute exacerbations of idiopathic pulmonary fibrosis. Am J Respir Crit Care Med 2007; 176: 636-643.

5 Kim DS, Park JH, Park BK, et al. Acute exacerbation of idiopathic pulmonary fibrosis: frequency and clinical features. Eur Respir J 2006; 27: 143-150.

6 Travis WD, Colby TV, Koss MN, et al. Lipoid pneumonia and chronic fibrosis. In: King DW, ed. Non-Neoplastic Disorders of the Lower Respiratory Tract. Washington, American Registry of Pathology and the Armed Forces Institute of Pathology, 2002; pp. 187-196.

7 Lee JS, Collard HR, Raghu G, et al. Does chronic microaspiration cause idiopathic pulmonary fibrosis? Am J Med 2010; 123: 304-311.

8 Tobin RW, Pope CE 2nd., Pellegrini CA, et al. Increased prevalence of gastroesophageal reflux in patients with idiopathic pulmonary fibrosis. Am J Respir Crit Care Med 1998; 158: 1804-1808.

9 Sweet MP, Patti MG, Leard LE, et al. Gastroesophageal reflux in patients with idiopathic pulmonary fibrosis referred for lung transplantation. J Thorac Cardiovasc Surg 2007; 133: 1078-1084.

10 Raghu G, Freudenberger TD, Yang S, et al. High prevalence of abnormal acid gastro-oesophageal reflux in idiopathic pulmonary fibrosis. Eur Respir J 2006; 27: 136-142.

11 Pellegrini CA, DeMeester TR, Johnson LF, et al. Gastroesophageal reflux and pulmonary aspiration: incidence, functional abnormality, and results of surgical therapy. Surgery 1979; 86: 110-119.

12 Ware LB, Matthay MA. The acute respiratory distress syndrome. N Engl J Med 2000; 342: 1334-1349.

13 Ward C, Forrest IA, Brownlee IA, et al. Pepsin like activity in bronchoalveolar lavage fluid is suggestive of gastric aspiration in lung allografts. Thorax 2005; 60: 872-874.

14 Blondeau K, Mertens V, Vanaudenaerde BA, et al. Gastro-oesophageal reflux and gastric aspiration in lung transplant patients with or without chronic rejection. Eur Respir J 2008; 31: 707-713.

15 Farrell S, McMaster C, Gibson D, et al. Pepsin in bronchoalveolar lavage fluid: a specific and sensitive method of diagnosing gastrooesophageal reflux-related pulmonary aspiration. J Pediatr Surg 2006; 41: 289-293.

16 Starosta V, Kitz R, Hartl D, et al. Bronchoalveolar pepsin, bile acids, oxidation, and inflammation in children with gastroesophageal reflux disease. Chest 2007; 132: 1557-1564.

17 Metheny NA, Chang YH, Ye JS, et al. Pepsin as a marker for pulmonary aspiration. Am J Crit Care 2002; 11: 150-154.

18 Stovold R, Forrest IA, Corris PA, et al. Pepsin, a biomarker of gastric aspiration in lung allografts: a putative association with rejection. Am J Respir Crit Care Med 2007; 175: 1298-1303.

19 American Thoracic Society. Idiopathic pulmonary fibrosis: diagnosis and treatment. International consensus statement. $\mathrm{Am} \mathrm{J}$ Respir Crit Care Med 2000; 161: 646-664.

20 Kim DS, Jeon YG, Shim TS, et al. The value of interleukin-12 as an activity marker of pulmonary sarcoidosis. Sarcoidosis Vasc Diffuse Lung Dis 2000; 17: 271-276. 
21 Akira M, Hamada $\mathrm{H}$, Sakatani $\mathrm{M}$, et al. CT findings during phase of accelerated deterioration in patients with idiopathic pulmonary fibrosis. AJR Am J Roentgenol 1997; 168: 79-83.

22 Patti MG, Goldberg HI, Arcerito M, et al. Hiatal hernia size affects lower esophageal sphincter function, esophageal acid exposure, and the degree of mucosal injury. Am J Surg 1996; 171: 182-186.

23 Raghu G, Yang ST, Spada C, et al. Sole treatment of acid gastroesophageal reflux in idiopathic pulmonary fibrosis: a case series. Chest 2006; 129: 794-800.
24 Linden PA, Gilbert RJ, Yeap BY, et al. Laparoscopic fundoplication in patients with end-stage lung disease awaiting transplantation. J Thorac Cardiovasc Surg 2006; 131: 438-446.

25 Kinder BW, Brown KK, Schwarz MI, et al. Baseline BAL neutrophilia predicts early mortality in idiopathic pulmonary fibrosis. Chest 2008; 133: 226-232.

26 Ufberg JW, Bushra JS, Patel D, et al. A new pepsin assay to detect pulmonary aspiration of gastric contents among newly intubated patients. Am J Emerg Med 2004; 22: 612-614. 